\title{
A Numerical Study of Wind Flow Over a Coal Storage Shelter
}

\author{
Tomáš Bodnár ${ }^{1}$, Luděk Beneš ${ }^{1}$, Luboš Pirkl ${ }^{1}$, Eva Gulíkováa ${ }^{2}$ \\ ${ }^{1}$ Department of Technical Mathematics, Faculty of Mechanical Engineering, Czech Technical University in Prague \\ ${ }^{2}$ Ecoprogress a.s., Most, Czech Republic
}

Corresponding author: Tomas.Bodnar@fs.cvut.cz

\begin{abstract}
This paper presents some of the main numerical results obtained while simulating the wind flow over a shelter covering a coal storage. The aim of this numerical study was to evaluate the change in flow patterns caused by adding an impermeable wall to the originally open shelter. The numerical simulations of selected two-dimensional cases were performed using an open-source CFD code. The flow model is based on Reynolds-Averaged Navier-Stokes Equations solved using a finite-volume method on a structured grid. The turbulence is parametrized using the standard $k-\epsilon$ model. Two shelter wall configuration variants are evaluated, and are compared with the original open shelter setup.
\end{abstract}

Keywords: finite-volume, Navier-Stokes equations, turbulence.

\section{Introduction}

This study is motivated by the needs of industrial coal processing. Coal often has to be transported, handled and stored in close proximity to inhabited areas. The coal dust produced during these processes is a major pollutant that has a serious negative impact on human health. Air-drifted coal dust is also a major hazard due to its explosivity at high concentrations. Coal is often handled in the open air, covered only by simple open shelters, consisting of just a roof without any walls. This protects the coal and the processing technology from major weather factors, such as rain, snow and direct sunshine. It also maintains low dust concentrations inside these shelters, which greatly reduces the risk of an explosion. This open configuration has many advantages, including structural simplicity and therefore low cost. In order to reduce pollution (by dust or noise) in surrounding areas, it was decided to build a wall that will at least partially enclose the building and prevent the escape of pollution. The aim of this study is to provide some information about how the newly-built wall will affect the flow, and about its possible impact on pollution dispersion.

\section{Mathematical Model}

Typical atmospheric flows are incompressible and turbulent. Flows of this type have been modeled e.g. in our previous works $[4,7,8]$. The effect of obstacles on pollution dispersion in the atmosphere was also studied in [5] or [6]. The influence of thermal stratification was included in $[1,2,3]$, where we have also demonstrated the influence of various numerical discretization techniques.

Similar problems of atmospheric flows over various obstacles are often studied in the available literature. Most studies however only consider smooth, hill-like obstacles. This is e.g. the case of the study of the wake flows behind 2D polynomial hills in [9], and the flow over a $2 \mathrm{D}$ sinusoidal topography with various hill slopes in [18]. More recent papers [17] and [21] include some comparisons of experimental and numerical data. The case of atmospheric flow over multiple $2 \mathrm{D}$ hills is investigated experimentally and compared to CFD solutions in [12]. The case of non-smooth obstacles was investigated e.g. in $[22,27,30,31,32]$. A comparison between experimental data and numerical simulations can be found in [25]. Coal dust and sand dispersion in the presence of porous fences has been investigated e.g. in $[23,24,33,26]$.

\subsection{Flow Model}

The model chosen for the study presented here is based on Reynolds-Averaged Navier-Stokes equations supplemented by the standard $k-\epsilon$ turbulence closure. The governing system consists of the conservation of mass and linear momentum written for Reynolds-Averaged mean quantities, i.e. velocity $\boldsymbol{v}=\operatorname{col}(u, v, w)$ and pressure $p$. Density $\rho$ is considered constant in this case. Volume forces (gravity, Coriolis, etc.) are neglected.

The resulting system can be written in conservative form as: 


$$
\begin{gathered}
\boldsymbol{\nabla} \cdot \boldsymbol{v}=0 \\
\frac{\partial \rho \boldsymbol{v}}{\partial t}+\nabla \cdot(\rho \boldsymbol{v} \otimes \boldsymbol{v})=-\boldsymbol{\nabla} p \\
+\boldsymbol{\nabla} \cdot\left[K\left(\boldsymbol{\nabla} \boldsymbol{v}+\boldsymbol{\nabla}^{T} \boldsymbol{v}\right)\right]
\end{gathered}
$$

The turbulent diffusion $K=\mu+\mu_{T}$ is equal to the sum of molecular (laminar) viscosity $\mu$ and turbulent (eddy) viscosity $\mu_{T}$. The turbulent viscosity is evaluated using a suitable turbulence model.

\subsection{Turbulence Model}

The standard $k-\epsilon$ model was chosen to account for the effects of turbulence. The governing equations for turbulent kinetic energy $k$ and rate of dissipation $\epsilon$ can be written in the following form:

$$
\begin{aligned}
\frac{\partial \rho k}{\partial t}+\nabla \cdot(\rho k \boldsymbol{v})=\nabla & \cdot\left[\left(\mu+\frac{\mu_{T}}{\sigma_{k}}\right) \nabla k\right] \\
+ & P_{k}-\rho \epsilon \\
\frac{\partial \rho \epsilon}{\partial t}+\nabla \cdot(\rho \epsilon \boldsymbol{v})=\nabla & \cdot\left[\left(\mu+\frac{\mu_{T}}{\sigma_{\epsilon}}\right) \nabla \epsilon\right] \\
+ & C_{1} \frac{\epsilon}{k} P_{k}-C_{2} \rho \frac{\epsilon^{2}}{k}
\end{aligned}
$$

The production of turbulent kinetic energy is computed from the strain rate tensor $\boldsymbol{S}=\left(\boldsymbol{\nabla} \boldsymbol{v}+\boldsymbol{\nabla}^{T} \boldsymbol{v}\right) / 2$ as

$$
P_{k}=\mu_{T} S^{2} \quad \text { where } \quad S=\sqrt{2 S: S}
$$

The turbulent viscosity is then calculated using

$$
\mu_{T}=C_{\mu} \rho \frac{k^{2}}{\epsilon} .
$$

The model coefficients are $C_{\mu}=0.09, C_{1}=1.44$, $C_{2}=1.92, \sigma_{k}=1.0, \sigma_{\epsilon}=1.3$.

\section{Computational Setup}

The computational setup is based on a $2 \mathrm{D}$ rectangular domain. The lower boundary is formed by an impermeable, no-slip wall. The wind flow enters the domain from the left side, parallel to the wall. Three different shelter wall variants are tested:

V1 - The wall is placed on the downwind side of the shelter. It has small gap in the upper part close to the roof.

V2 - Similar to variant V1, but the gap in the upper part is closed. The shelter is fully closed on the downwind side.

V3 - Similar to variant V2, but the wall has a small opening close to the ground.

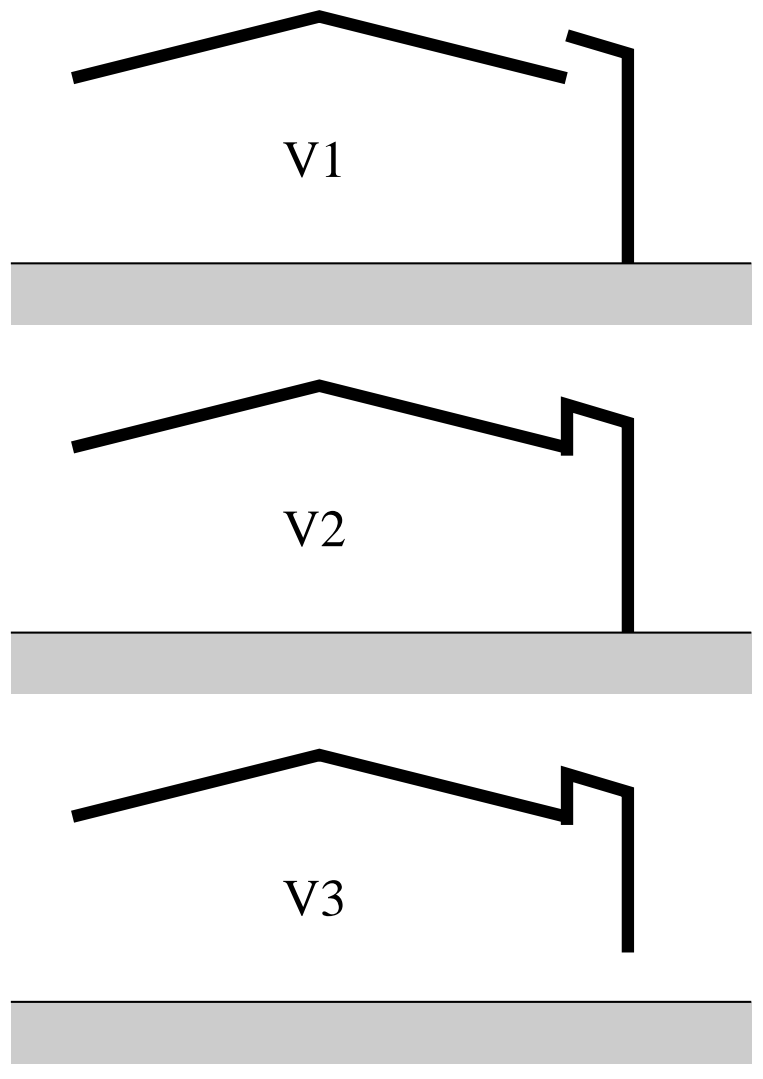

Figure 1: Sketch of the geometry

A sketch of the geometrical configuration for all three variants can be found in Figure 1. The domain size is $80 \times 25$ meters, with the shelter approximately $10 \times 4$ meters in size.

\section{Numerical Results}

The numerical simulations were performed using the OpenFOAM open source CFD software package. The solver is based on finite-volume discretization on structured, hexahedral cells. The space discretization is central, second order, cell centered. Pressure-velocity coupling is carried out using the PISO algorithm (Pressure Implicit with Splitting of Operators). The time integration is implicit, performed using a segregated linear solver by preconditioned bi-conjugate gradient method. The preconditioner is based on diagonal incomplete LU decomposition. The code uses MPI for parallelization.

The wind comes from the left side at (uniform) speed $10 \mathrm{~m} / \mathrm{s}$. The flow patterns for all three variants V1, V2 and V3 are shown in Figures 2-4. It is immediately evident the the variant V1 (with the upper gap) generates a massive recirculation zone on the downwind side of the shelter. The air passing through the shelter leaves the shelter at the height of the roof, which will contribute largely to spreading 
the dust generated inside the shelter over very large distances. Variant V2 is not acceptable, because it does not allow the coal dust to be washed out of the shelter by the wind. This can lead to high dust concentrations inside the shelter, and thus increases the risk of an explosion. This variant was included only for comparison. The best variant seems to be V3, where the ventilation gap has been placed close to the ground. This keep all the dust close to the ground, where it can easily sediment. Details of the flow patterns in the proximity of the shelter are shown in Figure 5.

The horizontal velocity fields ${ }^{1}$ shown in Figures $6-8$ again confirm that the worst variant is $\mathrm{V} 1$, where the flow speeds up significantly. This spreads the pollution over much larger distances. The structural loads for each of the shelter configurations can be estimated from the pressure fields shown in Figures 911. The force acting on various parts of the shelter can be evaluated from the pressure differences between the inner and outer parts of the building (wall, roof, etc.). The comparison of the pressure fields also seems to indicate that the loads on the shelter are much smaller for variant V3.

The pollution dispersion is strongly affected by the turbulence. The turbulent diffusion characteristics can be estimated using the turbulent kinetic energy shown in Figures 12-14. Shelter variant V3 generates much less turbulence than variant V1. This can contribute to faster dust sedimentation and consequently to lower pollution in more distant areas.

\section{Conclusions \& Remarks}

The numerical simulations have clearly shown that there are big differences between the flow-fields for the three configurations. On the basis of the numerical results, variant V3 seems to be the best choice. It maintains some flow passing through the shelter, reducing high dust concentrations, but it keeps the flow (carrying the dust) close to the ground. This type of flow helps heavy coal dust particles to drop out of the flow and sediment closer to the shelter, reducing the environmental pollution in more distant areas, which may be inhabited.

\section{Acknowledgements}

Financial support for this project was provided by grant TA01020428 of the Technological Agency of the Czech Republic.

\footnotetext{
${ }^{1}$ All results are presented in SI units, i.e. distances in $\mathrm{m}$, velocities in $\mathrm{m} \cdot \mathrm{s}^{-1}$ and pressure in $\mathrm{Pa}$.
}

\section{References}

[1] L. Beneš, J. Fürst, and P. Fraunié. Comparison of two numerical methods for the stratified flow. Computers \&f Fluids, 46(1):148-154, 2011.

[2] T. Bodnár and L. Beneš. On some high resolution schemes for stably stratified fluid flows. In Finite Volumes for Complex Applications VI, Problems $\&$ Perspectives, volume 4 of Springer Proceedings in Mathematics, pages 145-153. Springer Verlag, 2011.

[3] T. Bodnár, L. Beneš, P. Fraunié, and K. Kozel. Application of compact finite-difference schemes to simulations of stably stratified fluid flows. $A p$ plied Mathematics and Computation,. 219:33363353, 2012.

[4] I. Sládek, T. Bodnár, K. Kozel, On a numerical study of atmospheric $2 \mathrm{D}$ and $3 \mathrm{D}$ - flows over a complex topography with forest including pollution dispersion, Journal of Wind Engineering and Industrial Aerodynamics 95:1424-1444, 2007.

[5] T. Bodnár, L. Beneš, K. Kozel, Numerical simulation of flow over barriers in complex terrain, $I l$ Nuovo Cimento C 31 (5-6):619-632, 2008.

[6] L. Beneš, T. Bodnár, P. Fraunié, K. Kozel, Numerical modelling of pollution dispersion in $3 \mathrm{D}$ atmospheric boundary layer, in: B. Sportisse (Ed.), Air Pollution Modelling and Simulation, Springer Verlag, 2002, pp. 69-78.

[7] L. Matějíček, Z. Jaňour, L. Beneš, T. Bodnár, E. Gulíková, Spatio - temporal modelling of dust transport over surface mining areas and neighbouring residential zones, Sensors 8 (6):3830$3847,2008$.

[8] T. Bodnár, K. Kozel, P. Fraunié, Z. Jaňour, Numerical simulation of flow and pollution dispersion in 3D atmospheric boundary layer, Computing and Visualization in Science 3 (1-2):3-8, 2000 .

[9] G. P. Almeida, D. F. G Durão, and M. V. Heitor. Wake flows behind two-dimensional model hill. Experimental Thermal and Fluid Science, 7:87101, 1993.

[10] S. P. S. Arya, M. E. Capuano, and L. C. Fagen. Some fluid modeling studies of flow and dispersion over two-dimensional low hills. Atmospheric Environment, 21(4):753-764, 1987.

[11] T. Bodnár, K. Kozel, Ph. Fraunié, and L. Beneš. Numerical modelling of pollution dispersion in complex terrain. In Air Pollution IX., pages 85-94. WIT Press, 2001. 


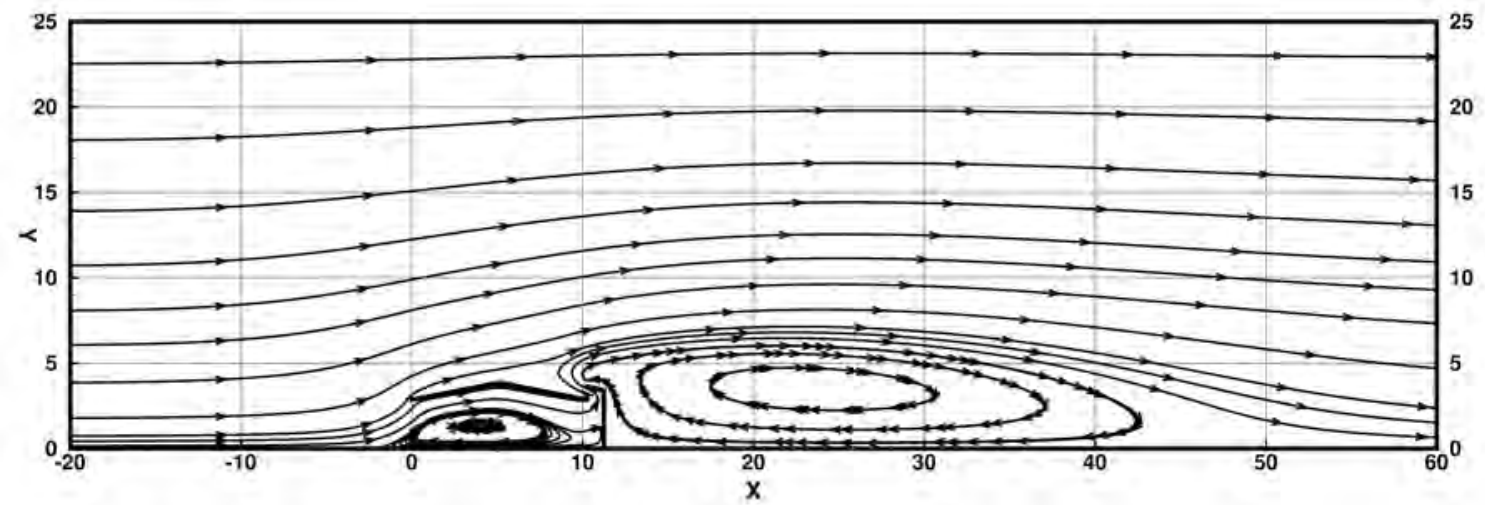

Figure 2: Streamlines - Variant V1

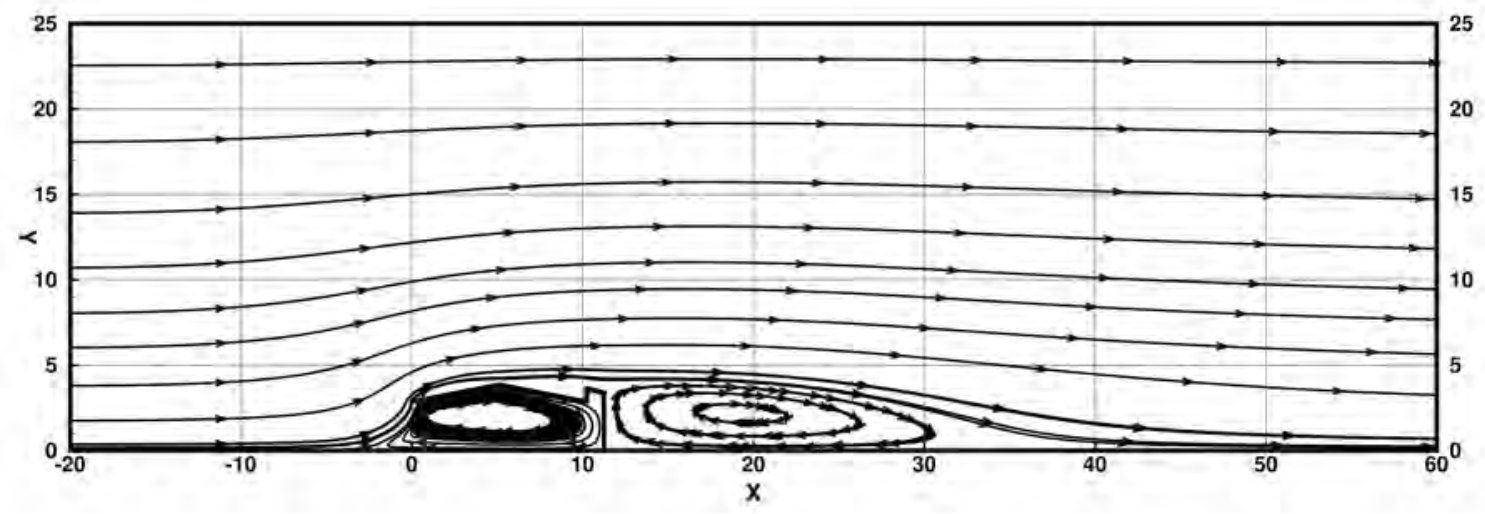

Figure 3: Streamlines — Variant V2

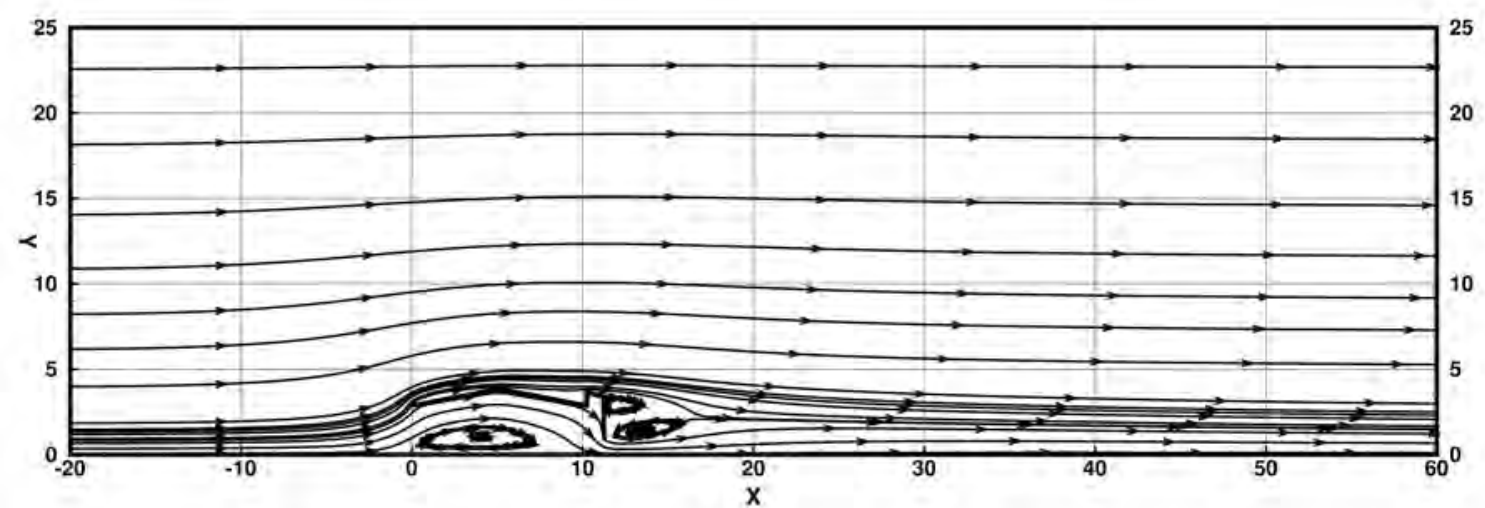

Figure 4: Streamlines - Variant V3

[12] P. Carpenter and N. Locke. Investigation of wind speeds over multiple two-dimensional hills. Journal of Wind Engineering and Industrial Aerodynamics, 83:109-120, 1999.

[13] I. P. Casro and D. D. Apsley. Flow and dispersion over hills: Comparison between numerical predictions and experimental data. Journal of wind engineering and industrial aerodynamics, (67 \& 68):375-386, 1997.
[14] I. P. Castro and D. D. Apsley. Flow and dispersion over topography: A comparison between numerical and laboratory data for two-dimensional flows. Atmospheric Environment, 31(6):839-850, 1997.

[15] I. P. Castro and W. H. Snyder. A wind tunnel study of dispersion from sources downwind of three-dimensional hills. Atmospheric Environment, 16:1869-1887, 1982. 

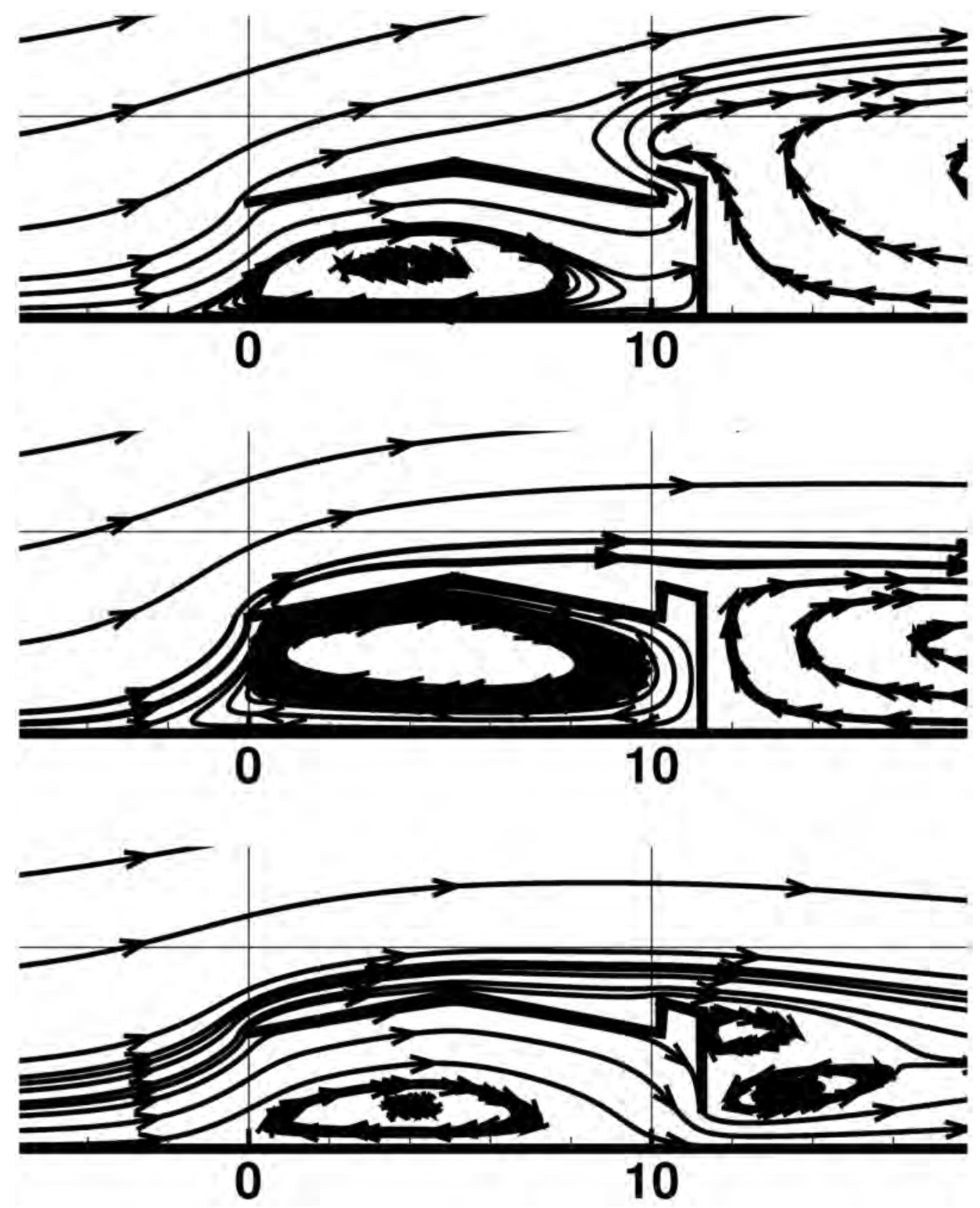

Figure 5: Streamlines detail — Variants V1-V3

[16] G. Crooks and S. Ramsay. A wind tunnel study of mean and fluctuating concentrations in a plume dispersion over two-dimensional hill. Boundary Layer Meteorology, 66:155-172, 1993.

[17] A. D. Ferreira, A. M. G. Lopes, D. X. Viegas, and A. C. M. Sousa. Experimental and numerical simulation of flow around two-dimensional hills. Journal of Wind Engineering and Industrial Aerodynamics, 54/55:173-181, 1995.

[18] A. D. Ferreira, M. C. G. Silva, D. X. Viegas, and A. G. Lopes. Wind tunnnel simulation of the flow around two-dimensional hills. Journal of
Wind Engineering and Industrial Aerodynamics, 38:109-122, 1991.

[19] W. Gong. A wind tunnel study of turbulent dispersion over two- and three-dimensional gentle hills from upwind point sources in neutral flow. Boundary Layer Meteorology, 54:211-230, 1991.

[20] W. Gong and A. Ibbetson. A wind tunnel study of turbulent flow over model hills. Boundary Layer Meteorology, 49:113-148, 1989.

[21] H. G. Kim, C. M. Lee, H. C. Lim, and N. H. Kyong. An experimental and numerical study on the flow over two-dimensional hills. Journal of 


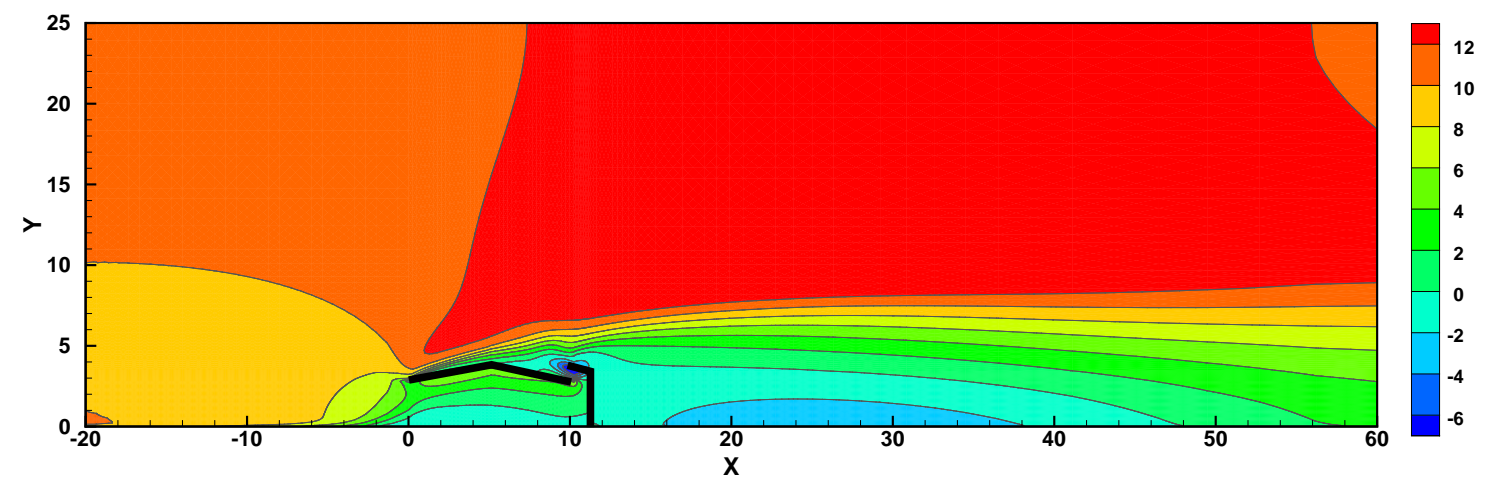

Figure 6: Horizontal velocity contours — Variant V1

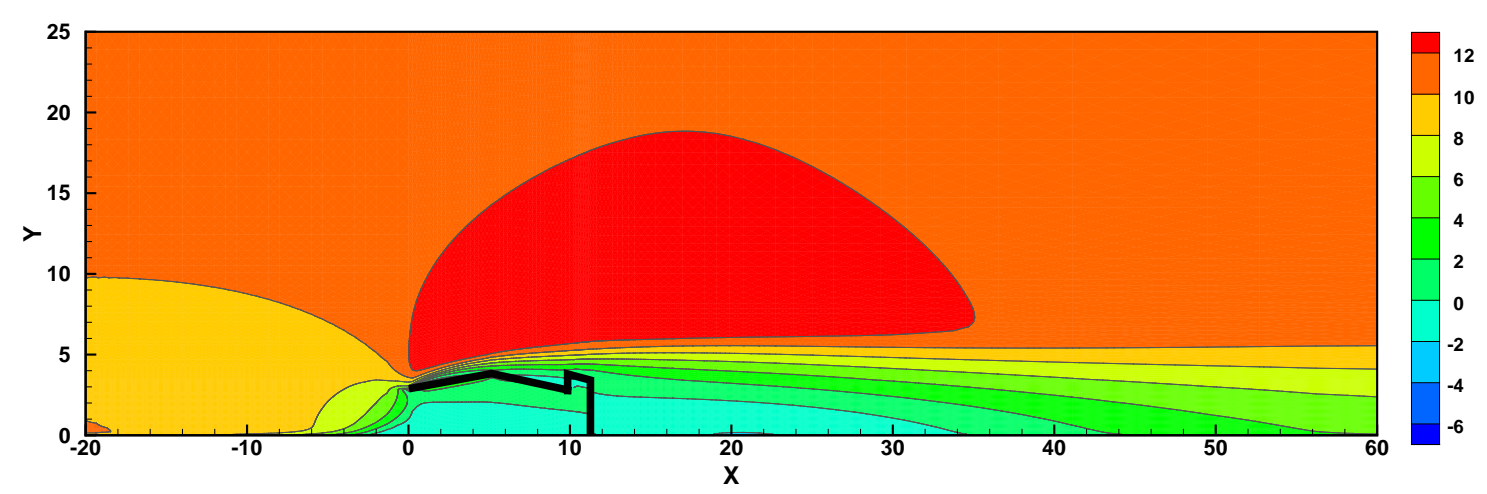

Figure 7: Horizontal velocity contours — Variant V2

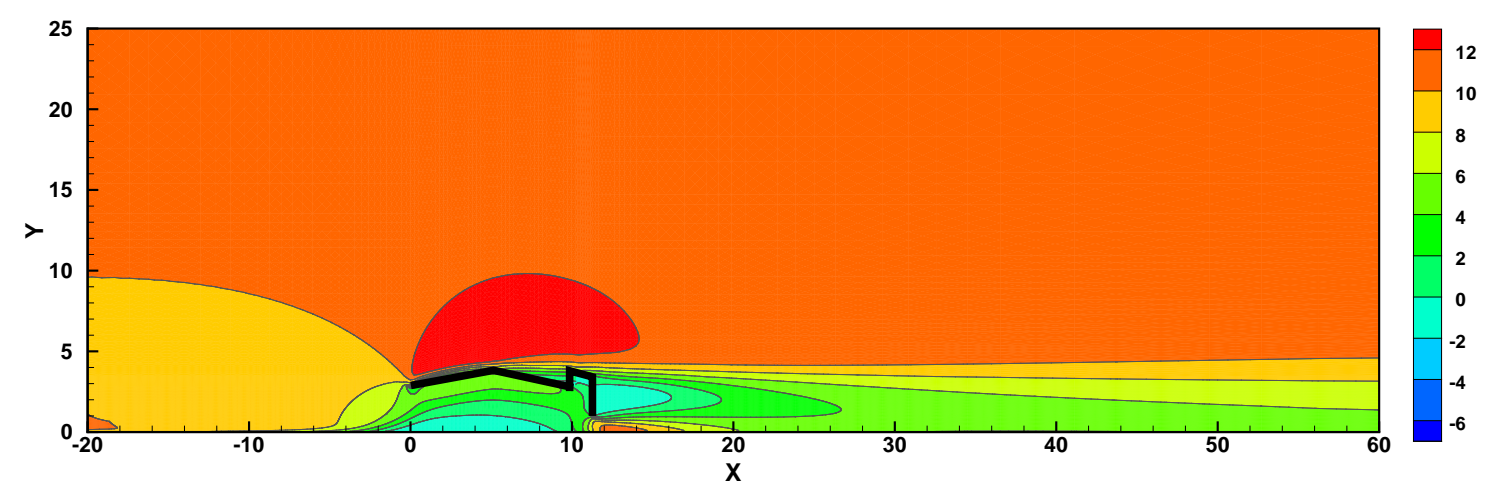

Figure 8: Horizontal velocity contours — Variant V3

Wind Engineering and Industrial Aerodynamics, 66(1):17-33, 1997.

[22] S. J. Lee and H. B. Kim. Laboratory measurements of velocity and turbulence field behind porous fences. Journal of Wind Engineering and Industrial Aerodynamics, 80:311-326, 1999.

[23] S. J. Lee and C. W. Park. The shelter effect of porous wind fences on coal piles in POSCO open storage yard. Journal of Wind Engineering and Industrial Aerodynamics, 84:101-118, 2000.
[24] S. J. Lee, K. C. Park, and C. W. Park. Wind tunnel observations about the shelter effect of porous fences on the sand particle movements. Atmospheric Environment, 36:1453-1463, 2002.

[25] A. R. Packwood. Flow through porous fences in thick boundary layers: comparisons between laboratory and numerical experiments. Journal of Wind Engineering and Industrial Aerodynamics, 88:75-90, 2000.

[26] C. W. Park and S. J. Lee. Verification of the 


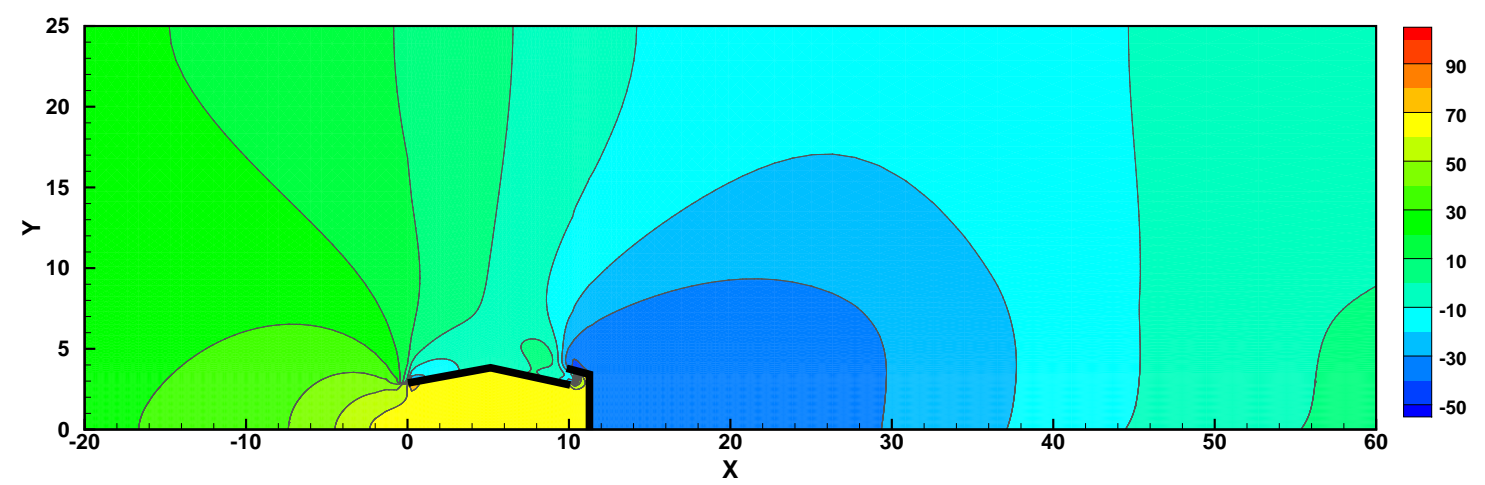

Figure 9: Pressure contours — Variant V1

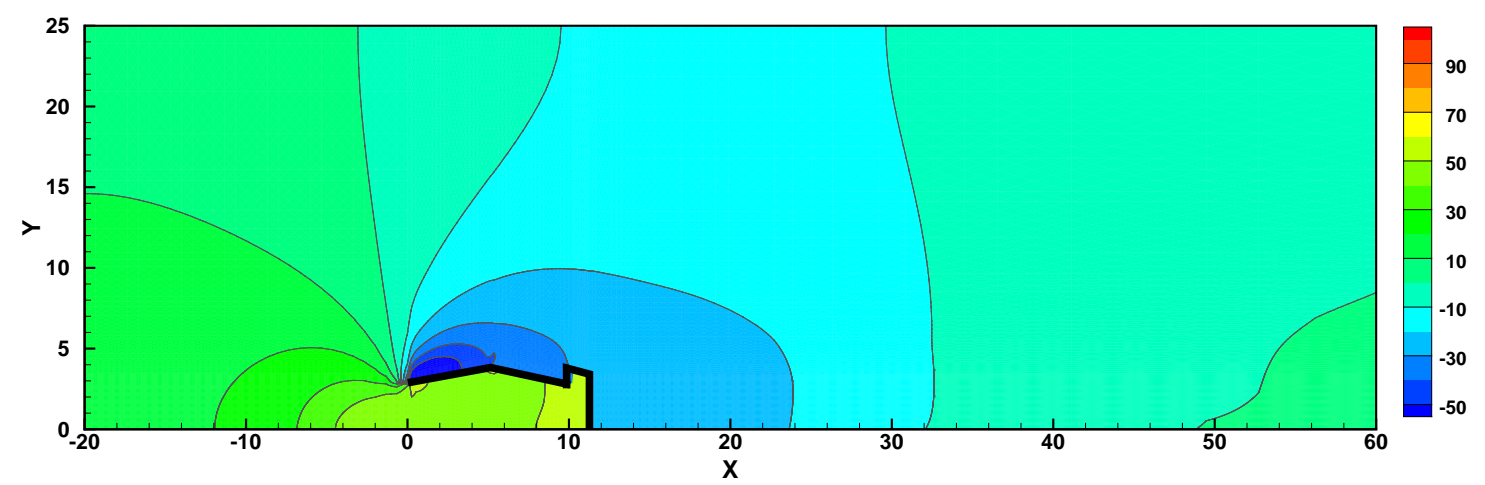

Figure 10: Pressure contours - Variant V2

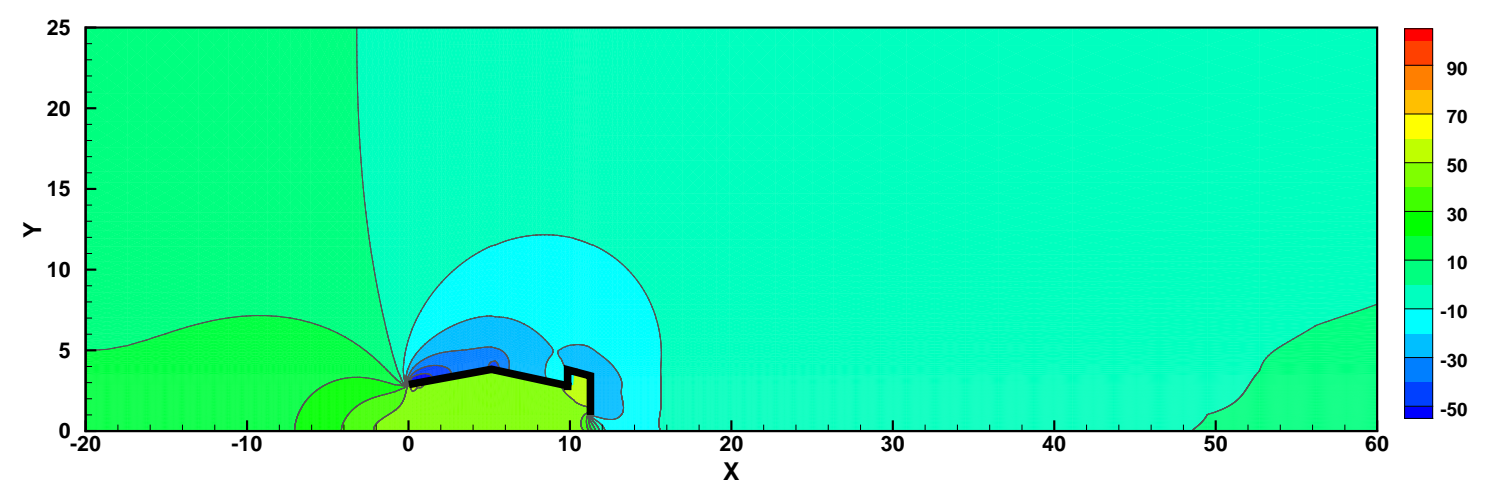

Figure 11: Pressure contours — Variant V3

shelter effect of a windbreak on coal piles in the POSCO open storage yards at the Kwang-Yang works. Atmospheric Environment, 36:2171-2185, 2002.

[27] C. W. Park and S. J. Lee. Experimental study on surface pressure and flow structure around a triangular prism located behind a porous fence. Journal of Wind Engineering and Industrial Aerodynamics, 91:165-184, 2003.

[28] W. H. Snyder. Fluid modeling applied to atmo- spheric diffusion in complex terrain. Atmospheric Environment, 24A(8):2071-2088, 1990.

[29] W. H. Snyder and R. E. Britter. A wind tunnel study of the flow structure and dispersion from sources upwind of three-dimensional hills. Atmospheric Environment, 21:735-751, 1987.

[30] H. Wang and E. S. Takle. On shelter efficiency of shelterbelts in oblique wind. Agricultural and Forest Meteorology, 81:95-117, 1996. 


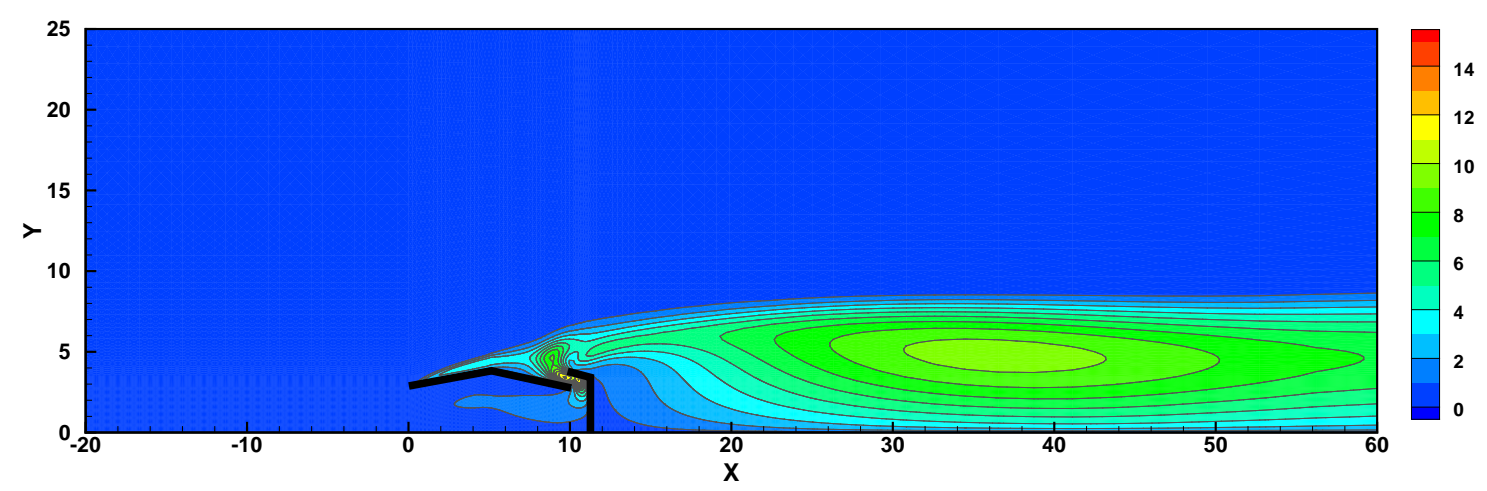

Figure 12: Turbulent kinetic energy contours — Variant V1

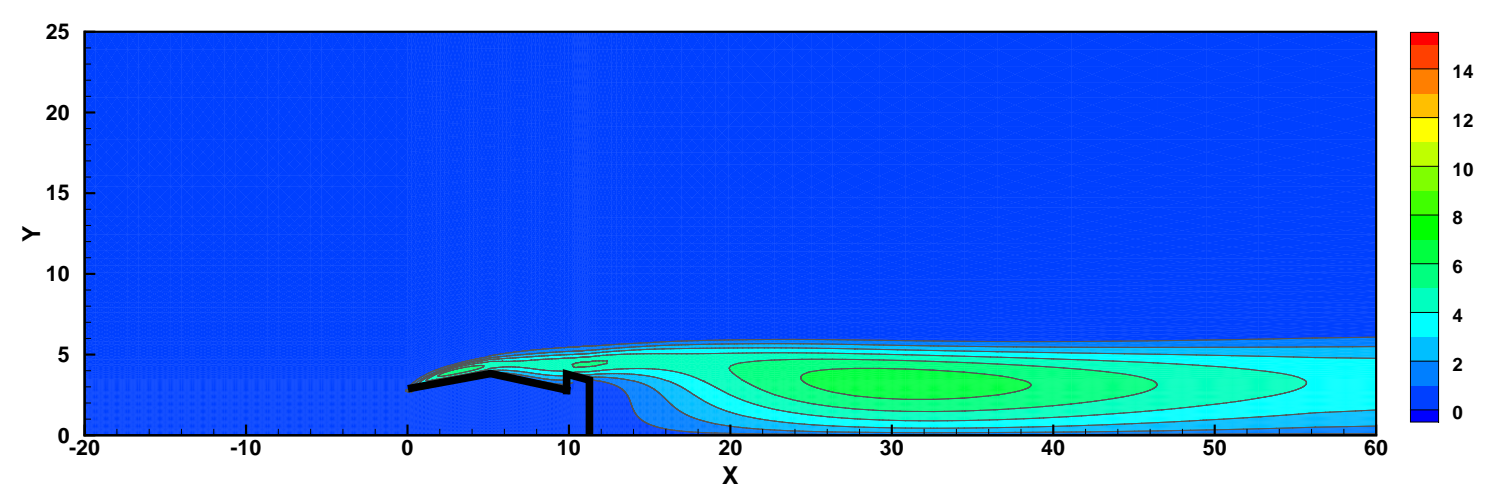

Figure 13: Turbulent kinetic energy — Variant V2

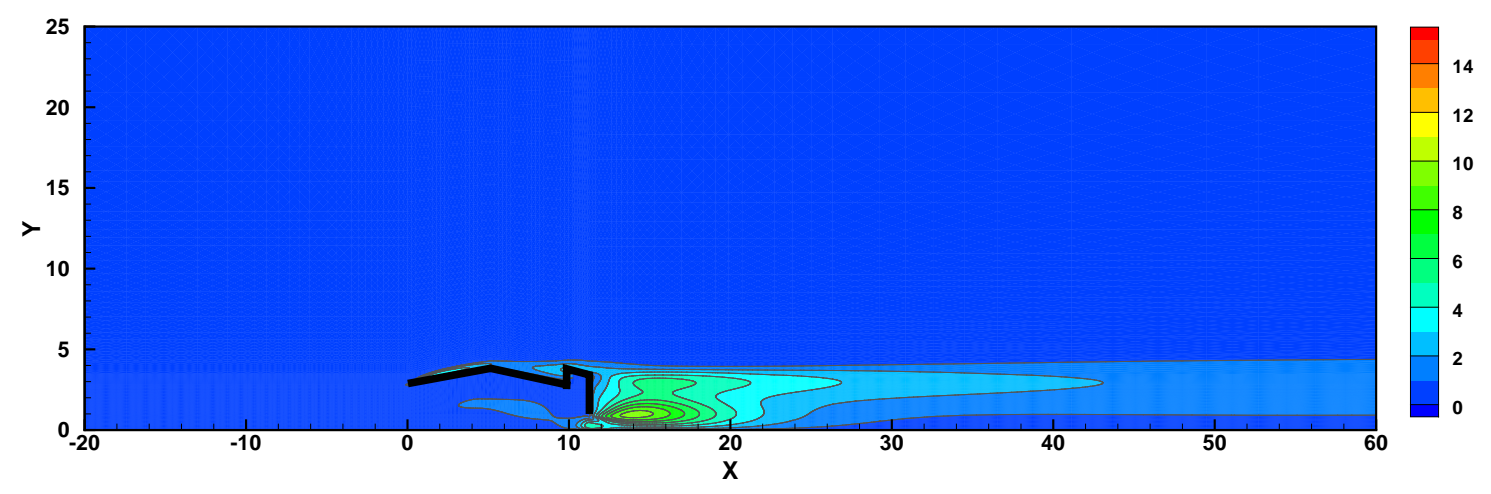

Figure 14: Turbulent kinetic energy — Variant V3

[31] J. D. Wilson and E. Yee. Calculation of winds disturbed by an array of fences. Agricultural and Forest Meteorology, (3082):1-20, 2002.

[32] S. C. Yaragal, H. S. G. Ram, and K. K. Murthy. An experimental investigation of flow fields downstream of solid and porous fences. Journal of Wind Engineering and Industrial Aerodynamics, 66:127-140, 1997.

[33] N. A. Zaghloul. Sand accumulation around porous fences. Atmospheric modelling and software, 12(2-3):113-134, 1997. 